\title{
Mapping Aboveground Biomass using Texture Indices from Aerial Photos in a Temperate Forest of Northeastern China
}

\author{
Shili Meng ${ }^{1}$, Yong Pang ${ }^{2, *}$, Zhongjun Zhang ${ }^{1}$, Wen Jia ${ }^{2}$ and Zengyuan $\mathrm{Li}^{2}$ \\ 1 College of Information Science and Technology, Beijing Normal University, Beijing 100875, China; \\ mengsl@mail.bnu.edu.cn (S.M.); zzj@bnu.edu.cn (Z.Z.) \\ 2 Institute of Forest Resource Information Techniques, Chinese Academy of Forestry, Beijing 100091, China; \\ jarywen@163.com (W.J.); lizy@caf.ac.cn (Z.L.) \\ * Correspondence: pangy@ifrit.ac.cn; Tel.: +86-10-62888847
}

Academic Editors: Cheng Wang, Peter Krzystek, Wei Yao, Yong Pang, Marco Heurich, Nicolas Baghdadi and Prasad S. Thenkabail

Received: 31 October 2015; Accepted: 7 March 2016; Published: 11 March 2016

\begin{abstract}
Optical remote sensing data have been considered to display signal saturation phenomena in regions of high aboveground biomass (AGB) and multi-storied forest canopies. However, some recent studies using texture indices derived from optical remote sensing data via the Fourier-based textural ordination (FOTO) approach have provided promising results without saturation problems for some tropical forests, which tend to underestimate AGB predictions. This study was applied to the temperate mixed forest of the Liangshui National Nature Reserve in Northeastern China and demonstrated the capability of FOTO texture indices to obtain a higher prediction quality of forest AGB. Based on high spatial resolution aerial photos (1.0 m spatial resolution) acquired in September 2009, the relationship between FOTO texture indices and field-derived biomass measurements was calibrated using a support vector regression (SVR) algorithm. Ten-fold cross-validation was used to construct a robust prediction model, which avoided the over-fitting problem. By further comparison the performance of the model estimates for greater coverage, the predicted results were compared with a reference biomass map derived from LiDAR metrics. This study showed that the FOTO indices accounted for $88.3 \%$ of the variance in ground-based AGB; the root mean square error (RMSE) was $34.35 \mathrm{t} / \mathrm{ha}$, and RMSE normalized by the mean value of the estimates was $22.31 \%$. This novel texture-based method has great potential for forest AGB estimation in other temperate regions.
\end{abstract}

Keywords: AGB; high spatial resolution image; aerial photos; FOTO indices; SVR; temperate forest; LiDAR

\section{Introduction}

Carbon dioxide is an important factor in climate change. The increase in $\mathrm{CO}_{2}$ accompanied by increasing atmospheric temperature may affect human activities as well as global sustainable development. Forests store carbohydrates synthesized from carbon dioxide during photosynthesis. Human and natural activities such as deforestation and degradation cause substantial releases of carbon dioxide, thus leading to great uncertainty about global change $[1,2]$. The influence of forest biomass on carbon cycles has long been recognized; therefore, an accurate assessment of forest biomass is required for understanding ecosystem changes. In general, three approaches are commonly applied for biomass estimations: field measurements, geographic information system (GIS), and remote sensing methods [3-6]. The traditional method of field measurement has historically been considered the most precise method, although field measurement is time consuming, labor intensive, subject to inaccessibility in remote areas, and may collect insufficient sample plots. GIS-based approaches have 
not been extensively applied to biomass estimations because of the inconvenience of establishing spatial and attribute databases [6]. Remote sensing techniques have attracted substantial attention for estimating aboveground biomass (AGB) because they enable relatively convenient data acquisition while maintaining an acceptable accuracy for AGB predictions in large areas.

Very high spatial resolution (VHSR) images contain abundant texture information, which characterizes the spatial and structural distribution of forest canopies. Thus, VHSR data possess an advantage over spectral responses to biomass estimation in forests with complex structures [7]. Texture indices derived from remote sensing data have been recognized as strong predictors for AGB estimation for forests [7-11]. Due to the promising performance for providing texture information, a well-establish texture-based method known as Fourier-based textural ordination (FOTO) was used in this research. The FOTO method uses a combination of Fourier transform and principal component analysis (PCA) to detect forest canopy structural heterogeneity [12,13]. Many studies have indicated that FOTO texture indices could be regarded as good predictors of AGB in tropical forests. The FOTO method has been applied to VHSR remote sensing data to derive forest biomass models in French Guiana [8,14-16], Malaysian Borneo [17,18], Brazil Amazonia [8], and the Western Ghats of India [19]. Theoretically, optical remote sensing technologies have a limited capability of predicting forest biomass, particularly for those mature forests which spectral responses become saturated [5,7]. Proisy et al. [14] implemented FOTO for coastal mangrove forests in French Guiana using IKONOS data; the results showed that saturation phenomena did not appear even for high biomass levels greater than $450 \mathrm{t} / \mathrm{ha}$. Singh et al. [18] indicated that the FOTO approach proved powerful in distinguishing different forest types and in developing individual biomass estimate models for various forest types in Malaysian Borneo. FOTO texture indices also demonstrated a strong correlation with forest AGB in Central Africa for $\mathrm{R}^{2}=0.85$; residual standard error $(\mathrm{RSE})=15 \%$ [11]. The above cases confirm the great potential of the FOTO method for generating remote sensing based AGB models for tropical regions.

With the development of Light Detection and Ranging (LiDAR) techniques since the 1990s, the capability of laser pulses to penetrate the forest canopy to the ground has allowed forest stand heights to be obtained with high accuracy. Lefsky et al. [20] proved that canopy height profiles are highly correlated with basal area and aboveground forest biomass. Due to the limitation of obtaining adequate field measurements, insufficient training data sets may decrease the accuracy and generalization of the prediction model. However, biomass maps derived from LiDAR data with sufficiently high precision could be used for validating other less proven predictions when estimating vertical structure, such as forest stand height and canopy height, as well as AGB over large areas [21-23].

The objective of this study is to explore the potential of FOTO indices for AGB estimation in a temperate forest. Based on the VHSR aerial photos (1.0 m spatial resolution) acquired in 2009, a machine learning (ML) model was used to calibrate the relationship between FOTO texture indices and field-derived biomass. ML techniques are increasingly used in remote sensing research to provide a robust method of modeling results and a higher generalization performance than linear or nonlinear models [13,24,25]. A support vector regression (SVR) algorithm was used for regression purposes in this study. The resulting maps of AGB were compared against estimations derived from airborne LiDAR data over the same area.

\section{Materials}

\subsection{Study Area}

The study site is situated in the Liangshui National Reserve (centered at $47^{\circ} 10^{\prime} 53^{\prime \prime} \mathrm{N}, 128^{\circ} 53^{\prime} 20^{\prime \prime} \mathrm{E}$, UTM Zone 52) of the province of Heilongjiang in Northeastern China (Figure 1). The Liangshui National Reserve was established in 1980 and protects the ecological system of conifer and broadleaf mixed forests. The study site covers an area of approximately $120 \mathrm{~km}^{2}$, and the forest cover accounts for more than 95\%. Altitudes range from 280 to $707 \mathrm{~m}$ above sea level. The terrain is a hilly landscape with surface slopes of mountainous areas reaching up to $40^{\circ}$. The region receives approximately 
$680 \mathrm{~mm}$ of precipitation per year, and the relative humidity is approximately $78 \%$. The annual mean temperature is approximately $-0.3^{\circ} \mathrm{C}$. The climate conditions of this subzone can be described as windy springs, with high temperatures and concentrated rainfall in summer, cool autumns, and long, cold, dry and snowy winters [26]. Undisturbed original red pines (Pinus koraiensis) are the dominant tree species, covering approximately $41 \mathrm{~km}^{2}$ in this reserve [27]; other protected tree species are present, including Betula platyphylla, Tilia amurensis, Populus davidiana, Quercus mongolica, Phllodendron amurense and Juglans mandshurica [28].

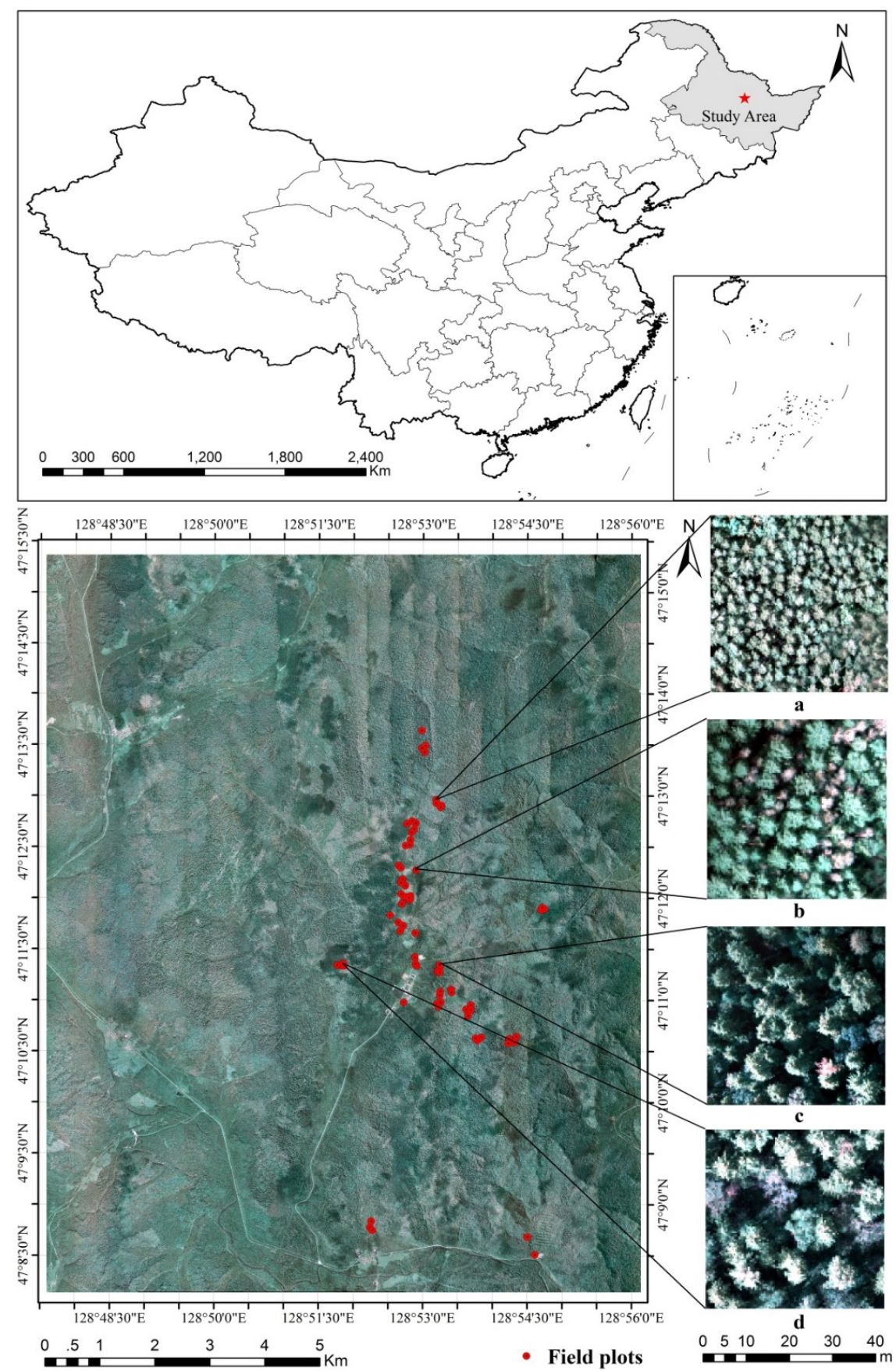

Figure 1. Location map of Liangshui National Nature Reserve in Northeastern China, aerial data were obtained for 26 flight strips in September of 2009. Seventy-four field plots measured in August 2009 are marked in red spots. Subplots of $(\mathbf{a}-\mathbf{d})$ show the samples for different forest canopy sizes (the average crown size for subplot (a) is $3.35 \mathrm{~m}$; (b) is $4.69 \mathrm{~m}$; (c) is $5.86 \mathrm{~m}$ and (d) is $7.57 \mathrm{~m}$ ). 


\subsection{Field Data}

The ground survey was conducted in August 2009. To achieve a robust prediction model, the stratified sampling frame was used, which contained three strata of coniferous forest, broadleaf forest, and mixed forest. For each strata, plots with different AGB levels were sampled. Seventy-four circular samples with a radius of $13.8 \mathrm{~m}$ were established (Figure 1). The plot area is approximately $600 \mathrm{~m}^{2}$, which is consistent with forest inventory plots in Heilongjiang. When the field plots are laid out, a rule was established so that each plot represents a large stand of over 3 ha. Within each plot, the diameter at breast high (DBH), tree species, tree height, under-branch height, and crown diameter of all of the individual trees with DBH greater than $5 \mathrm{~cm}$ was measured. DBH was recorded using a caliper. Two measurements of principal directions (north-south and east-west) for canopy crowns were obtained using measuring tape. The crown diameter was computed as the average of these two measurements. Tree height and under-branch height were measured with a laser altimeter (TruPulse 360B, Laser Technology Inc., Centennial CO, USA). The statistical results for some of the main field measurements are given in Table 1. The skewness for $\mathrm{DBH}$ is the largest of the three parameters $(\mathrm{DBH}$, tree height, and crown diameter), which indicates that the number of individual trees with a large size $(>40 \mathrm{~cm})$ is less than the number of trees with a medium size $(10-40 \mathrm{~cm})$. The distributions of tree height and crown diameter are more dispersive. Figure 2 shows the distribution for the recorded data from lower to higher tree height levels as well as from fine to coarse crown shapes. The position of each plot was recorded by a Trimble GeoXT GPS (GeoXT, Trimble Navigation Limited, Sunnyvale, USA); the position errors were less than $1 \mathrm{~m}$ after differential processing. Forest biomass was calculated using the allometric model developed by Wang [29], given in Equation (1), where $a$ and $b$ are the coefficients of the regression model. AGB for all of the individual trees was summed for each plot then converted to biomass density in tons per hectare ( $t / h a)$. The estimated AGB for 74 plots ranged from 25 to 445 t/ha, with an average biomass of $153.98 \pm 103.47 \mathrm{t} / \mathrm{ha}$.

$$
A G B=a D B H^{b}
$$

Table 1. Statistical results for the field measurements.

\begin{tabular}{cccccccc}
\hline Variables & Mean & Standard Deviation & Min & Median & Max & Skewness & Kurtosis \\
\hline DBH $(\mathrm{cm})$ & 16.33 & 11.33 & 2.10 & 13.31 & 98.70 & 2.47 & 8.47 \\
Tree height $(\mathrm{m})$ & 14.72 & 6.48 & 1.80 & 14.04 & 38.90 & 0.55 & -0.21 \\
Crown diameter(m) & 4.36 & 1.64 & 0.15 & 4.12 & 15.80 & 1.04 & 1.97 \\
\hline
\end{tabular}
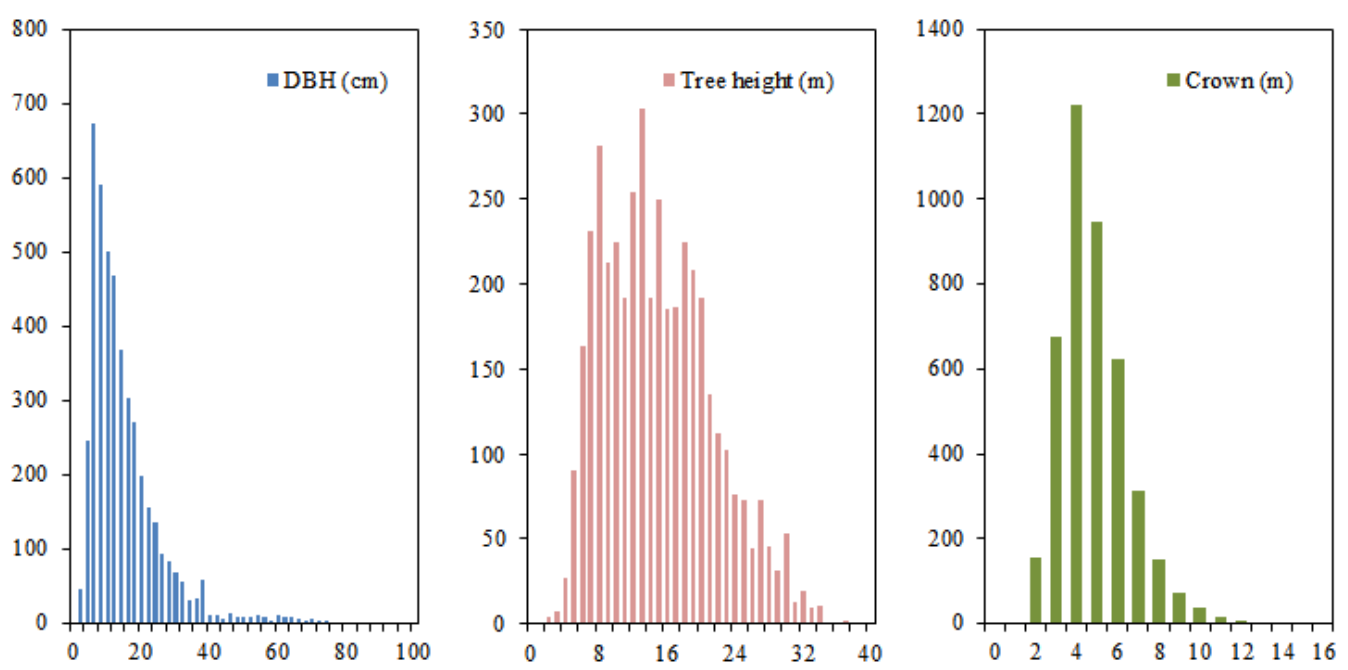

Figure 2. Histogram for recorded DBH, tree height and crown diameter variables. 


\subsection{Remote Sensing Data}

Remote sensing data collection was conducted on 4 September 2009 using a 22-megapixel DigiCAM-H/22 CCD camera. Weather that was cloud-free or with low cloud cover at a height above flight altitude was selected for the flight condition. A high sun elevation angle provides good illumination conditions and minimizes the topographic effect on optical data. Data collection occurred from 10:00 a.m. to 14:00 p.m. A Yun-5 fixed wing aircraft flew from north to south at a flight speed of 150 to $193 \mathrm{~km} / \mathrm{h}$ and at a flight altitude of $1070 \mathrm{~m}$ above sea level. Data were obtained for $26 \mathrm{flight}$ strips during the test flight. Aerial imagery acquired for this research consisted of data for three bands (the red band at $700 \mathrm{~nm}$, the green band at $540 \mathrm{~nm}$, and the blue band at $480 \mathrm{~nm}$ ) with $1.0 \mathrm{~m}$ spatial resolution (Figure 1). Preprocessing steps required for the CCD raw data included radiometric correction, atmospheric correction, and orthorectification. The three visible bands were averaged to generate a gray-level (0-255) image for the FOTO texture analysis. Some of the main technical parameters for airborne sensors are given in Table 2.

Table 2. Main technical parameters for airborne sensors.

\begin{tabular}{cccc}
\hline \multicolumn{3}{c}{ DigiCAM-H/22 } \\
\hline $\begin{array}{c}\text { Sensor size } \\
\text { Sensor dimensions }\end{array}$ & $5440 \times 4080$ & Pixel size & $9 \mu \mathrm{m}$ \\
& $36.72 \mathrm{~mm} \times 48.96 \mathrm{~mm}$ & Focal length & $50 \mathrm{~mm}$ \\
\hline Wavelength & Rieg1 LMS-Q560 (Full Waveform Digitization) & 2 points $/ \mathrm{m}^{2}$ \\
Pulse firing rate & $1550 \mathrm{~nm}$ & Point density & $\pm 30^{\circ}$ \\
\hline Pulse length & $100 \mathrm{kHz}$ & Scan angle range & $0.1 \mathrm{~m} / 0.03 \mathrm{~m}$ \\
Sampling interval & $3.5 \mathrm{~ns}$ & Surface point accuracy & \\
\hline
\end{tabular}

Airborne LiDAR data were collected concurrently with the aerial imagery. An LMS-Q560 LiDAR scanner (Riegl Laser Measurement Systems GmbH, Horn, Austria) was used to collect LiDAR point clouds during the flight. This small footprint LiDAR system achieved an average point density of 2 points per $\mathrm{m}^{2}$. The total coverage of the measurement area reached approximately $200 \mathrm{~km}^{2}$. The reference AGB map derived from LiDAR was generated by calibrating the relationship between LiDAR metrics and the AGB of the field plots. LiDAR point cloud data were classified onto ground points, vegetation points, and other points. A digital elevation model (DEM) was interpolated using ground points. Then, the heights of vegetation points were normalized according to their terrain elevation. We chose returns above $2 \mathrm{~m}$ as the vegetation point threshold for further LiDAR metrics calculation [30]. Several attributes were derived from the LiDAR point cloud data, including: every 10th percentile for the first return, i.e., $10 \%\left(h_{10}\right), 20 \%\left(h_{20}\right), \ldots, 90 \%\left(h_{90}\right), 100 \%\left(h_{100}\right)$, every one-tenth accumulation of canopy density, i.e., $10 \%\left(d_{10}\right), 20 \%\left(d_{20}\right), \ldots, 90 \%\left(d_{90}\right), 100 \%\left(d_{100}\right)$, and the mean height $\left(h_{m}\right)$ [31-33]. These LiDAR metrics data had a $10 \mathrm{~m}$ spatial resolution. Multiple linear regression was applied to calibrate the regression model. The optimal predicted model from the LiDAR data had a $\mathrm{R}^{2}$ of 0.82 and RMSE of $44.8 \mathrm{t} / \mathrm{ha}$ [28]. We produced a wall-to-wall forest AGB map and resampled the results to a $10 \mathrm{~m}$ spatial resolution (Figure 3). The white regions in Figure 3 represent the highest AGB, while black regions represent the lowest AGB. The AGB in the Liangshui Reserve (the center of the data) is higher than that of the surrounding forests. 


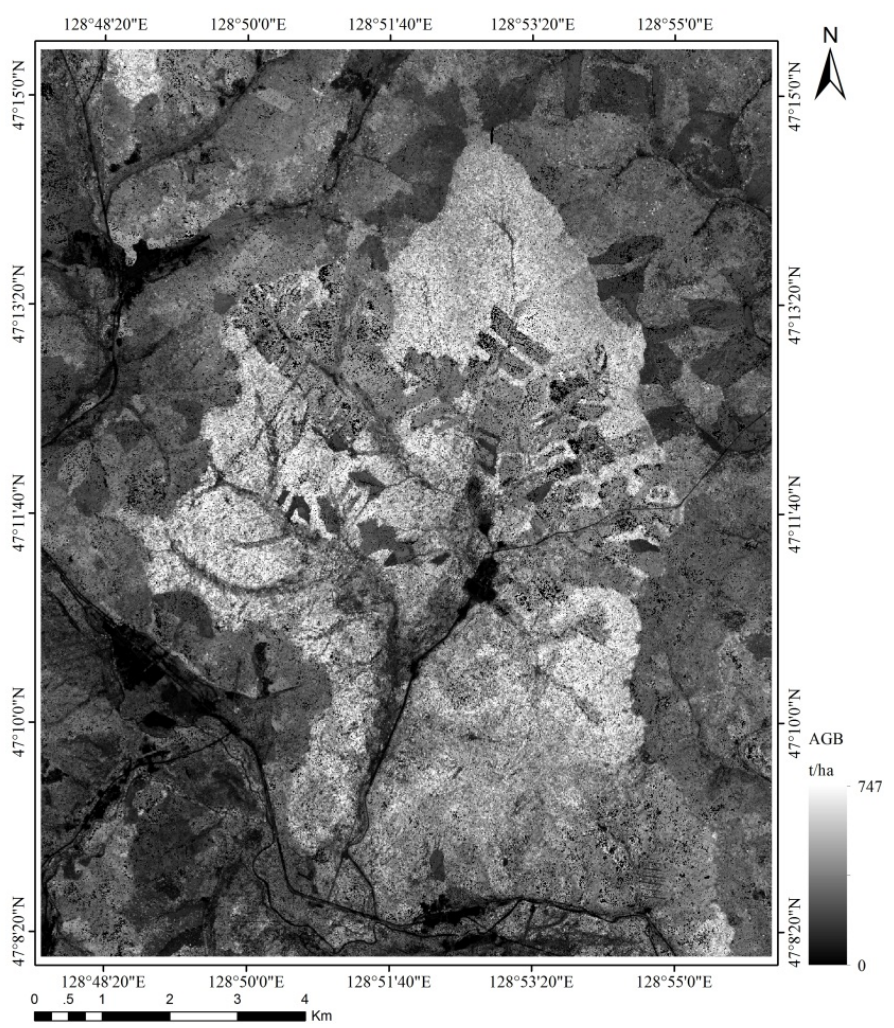

Figure 3. The wall-to-wall forest AGB map of Liangshui National Nature Reserve derived from LiDAR metrics $(245.27 \pm 92.91 \mathrm{t} / \mathrm{ha})$.

\section{Methodology}

The FOTO texture-based method extracted FOTO indices from the aerial photos, and an SVR algorithm was then used to calibrate the relationship between the FOTO texture indices and the biomass of the field plots. Figure 4 describes the workflow of AGB estimation and evaluation in this research.

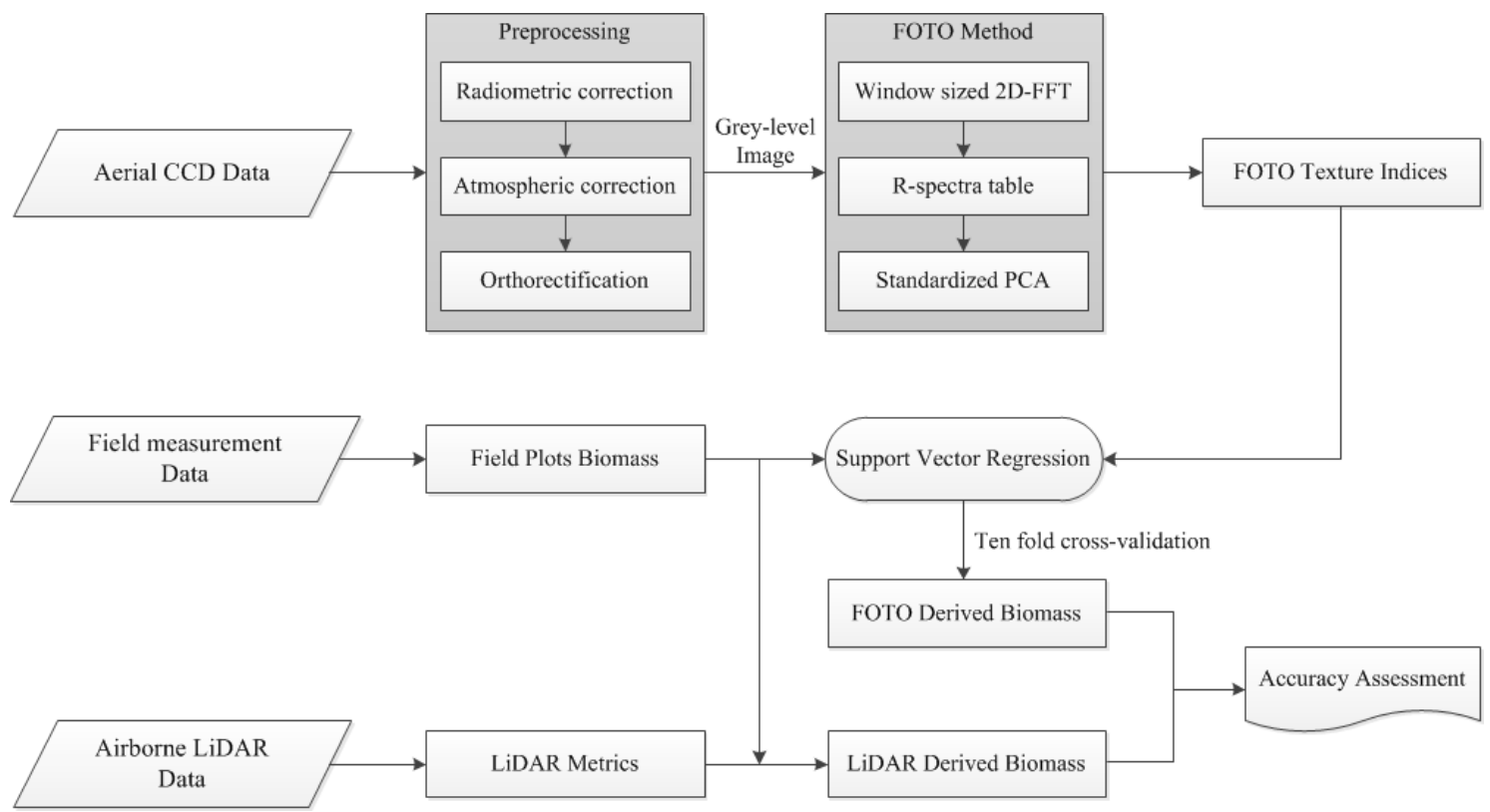

Figure 4. Research workflow of the AGB estimation and evaluation method. 


\subsection{FOTO Method}

We developed the texture-based FOTO analysis in the IDL environment (Interactive Data Language, Exelis Visual Information Solutions, Inc., Boulder, CO, USA). The gray-level image was first divided into $100 \mathrm{~m} \times 100 \mathrm{~m}$ square subsets by windowing the data successively from left to right and top to bottom. A window size was set to include at least five repetitions of the largest tree crown diameter [19,34]; a small window was unable to adequately capture large canopy features, whereas large windows could characterize landscape features rather than canopy crowns. A window size of $100 \mathrm{~m}$ was applied to derive FOTO indices in our research. Each window was subjected to two-dimensional fast Fourier transform (2D-FFT) analysis. Fourier analysis is based on the assumption that any continuous function can be decomposed into a series of sine and cosine waves of differing amplitudes and frequencies [35]. The canopy structure can be decomposed into a few spatial frequencies after 2D-FFT. A power spectrum called the radial spectrum ("r-spectrum") was then computed. A detailed description of r-spectra was presented in Couteron et al. [7]. R-spectrum provides the frequency distribution for the repetitive structure of forest canopy. The $r$ indicates the number of times that a pattern, here referring to the spatial structure of the forest canopy, reproduces itself within the given window. Therefore, an image with a coarse texture will yield a radial spectrum which is skewed toward low frequencies, while fine texture is expected to generate more balanced spectra [18]. FOTO indices are very sensitive to canopy structure; some situations such as gaps, fallen trees and the natural decaying of trees will cause bias in the computation of r-spectra. Therefore, incorrect cycle images should be removed from the procedure [17].

A general data table was constructed in which the row was the r-spectrum of each window, and the columns contained the spectral values related to a given wavenumber [36]. Principal component analysis (PCA) was then applied to this r-spectra, and the first three most prominent axes were used as FOTO texture indices. These three indices explained more than $85 \%$ of the variance, and the remaining axes could be ignored. Outputs for FOTO indices had the spatial resolution set equal to the window size in the previous selection.

\subsection{SVR and Validation}

We derived AGB models based on the FOTO texture variables and the field measured data using machine learning techniques such as support vector regression (SVR). ML models typically contain support vector machines (SVM), artificial neural networks (ANN), and classification and regression trees (CART). ML models are often superior to linear or logistic regression models because they make fewer assumptions about the data and the processes; moreover, they consider the accuracy of prediction as the ultimate goal. Linear models often assume that variables come from a known statistical distribution, which is often an oversimplification [37]. SVM is a supervised non-parametric statistical machine learning technique. Support vector classification (SVC) focuses on the purpose of classification decisions, whereas support vector regression focuses on the regression problem [21]. The choice of the kernel function and the hyper-parameters will affect the regression performance of the SVR. The kernel function enables SVR algorithms to project the training dataset from a low dimensional space into a higher dimensional feature space in which the regression optimization problem can be solved in a linearized manner [38]. The linear kernel corresponds to non-kernel SVR; the polynomial kernel performs well globally but achieves poorer performance in partial samples. The RBF function shows a superior performance and robust results over the linear kernel [39].

Some kernels are as follows:

I. The linear kernel:

$$
K\left(x_{i}, x_{j}\right)=x_{i} \cdot x_{j}
$$

II. The polynomial kernel:

$$
K\left(x_{i}, x_{j}\right)=\left(\left(x_{i} \cdot x_{j}\right)+1\right)^{d}
$$


III. The radial basis function (RBF) kernel:

$$
K\left(x_{i}, x_{j}\right)=\exp \left(-\frac{\left|x_{i}-x_{j}\right|^{2}}{\sigma^{2}}\right)
$$

IV. The sigmoid kernel:

$$
K\left(x_{i}, x_{j}\right)=\tanh \left(k\left(x_{i} \cdot x_{j}\right)-\delta\right)
$$

where $d$ is the degree of the polynomial, $\sigma^{2}$ denotes the radius of the RBF kernel, and $k$ is the inclination factor of the sigmoid function.

The SVR algorithm was implemented based on the Libsvm toolbox [40]. This toolbox has powerful functions to solve the problem of classification, regression, and distribution estimation. The process involves extracting a training dataset to obtain the regression model. After the Libsvm machine training process, the optimal model can predict information for the testing dataset [41]. In this study, the RBF kernel was applied to map the training data to a higher feature space. Outputs of the toolbox are the hyper-parameters of the regression model, including the mean squared error (MSE), the penalty parameter $C$, and the kernel parameter $\sigma^{2}$. The ability to generalize the RBF kernel becomes weaker as the parameter $\sigma^{2}$ increases. The penalty parameter $C$ is used to account for the penalized loss when the training error occurs. It specifies the trade-off between the SVR function and the input variables for which deviations larger than the loss function are tolerable [42].

The determination coefficient $\left(R^{2}\right)$ indicates the fitting degree of the independent variables based on the model to the dependent variables. A high value of $\mathrm{R}^{2}$ does not necessarily mean a good model. It may be easy to over-fit the training data, but the predictions on new data will become worse. It is essential to separate the samples into two parts to create a robust model. The "training data" were used for training a prediction model and the "validation data" were used for evaluating the adaptability of that model. To obtain a robust SVR model, ten-fold cross-validation was used, which avoids the over-fitting problem. Ten-fold cross-validation relies on the random grouping of data into 10 equivalent subsamples. Each subsample successively plays the role of a validation sample, which means that one tenth of the entire dataset was not included in the AGB model generated each time. After this operation, the cross-validation model with the smallest estimated risk would be selected $[43,44]$. We used 74 field-derived biomass measurements to calibrate and validate the FOTO model; then, the comparison between FOTO-predicted AGB and LiDAR-derived results was conducted by selecting validation samples $(n=417)$ randomly across the study area, and the validation samples were included different levels of AGB.

\section{Results and Discussion}

\subsection{Forest AGB Estimation Using FOTO Texture Indices}

The first three principal components of the r-spectra table explained $87 \%$ of the total variance in high resolution aerial data. Therefore, these FOTO texture indices were considered as predictors for biomass estimation purposes. The performance of the SVR model was evaluated by considering the accuracy of the ten models over ten computations. The best performance estimation results are shown in Figure 5. The FOTO method achieved a very strong correlation between field-measured AGB and SVR-predicted AGB, with $\mathrm{R}^{2}$ reaching 0.88 and an RMSE of $34.35 \mathrm{t} /$ ha (the corresponding relative RMSE is $22.31 \%$ ), which captures biomass variations at a high accuracy. The predicted results show good agreements because they are very close to the 1:1 correspondence lines with both higher (AGB $>350 \mathrm{t} / \mathrm{ha}$ ) and lower (AGB $<50 \mathrm{t} / \mathrm{ha}$ ) values (Figure $5 \mathrm{a}$ ). Figure $5 \mathrm{~b}$ illustrates the residuals between field-measured AGB and SVR-predicted AGB, which are unbiased with \pm 80 -t/ha deviations over the full range of biomass. Figure 6 shows the result of the SVR-predicted AGB map, with considerable variation from 26.51 to $465.73 \mathrm{t} / \mathrm{ha}$. 


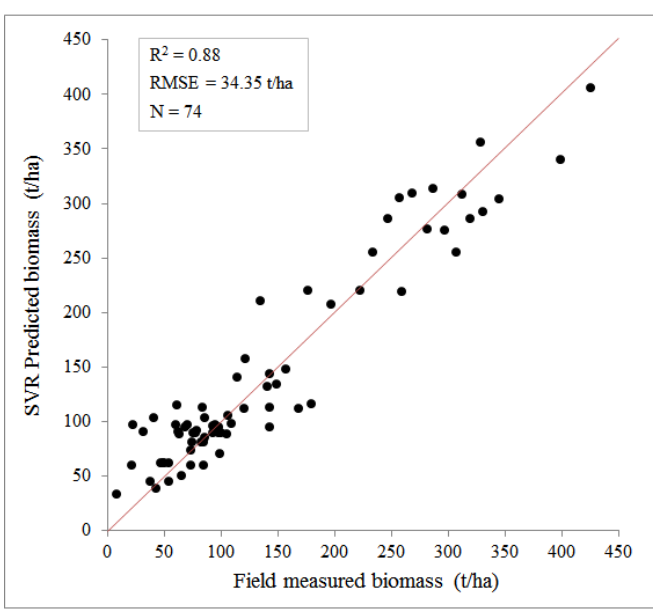

(a)

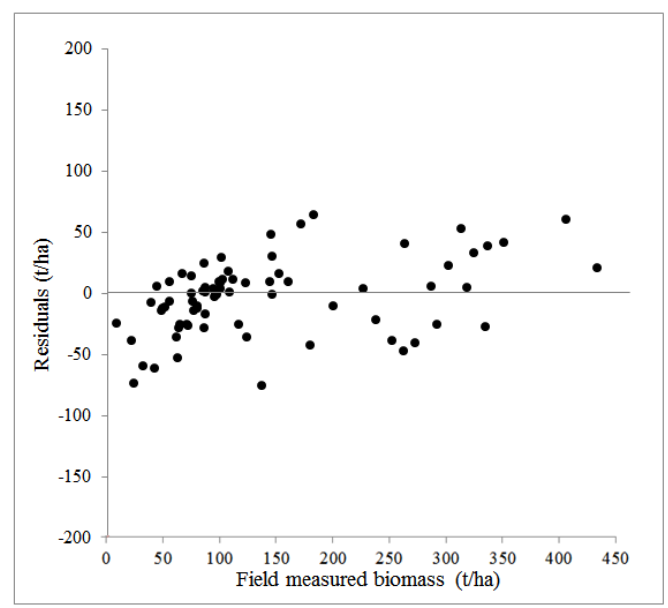

(b)

Figure 5. Field-measured AGB and the SVR-predicted AGB. (a) Scatter plot for the correlation between field-measured AGB and SVR-predicted AGB; (b) the residuals between field-measured AGB and SVR-predicted AGB. The red line represents the 1:1 correspondence line.

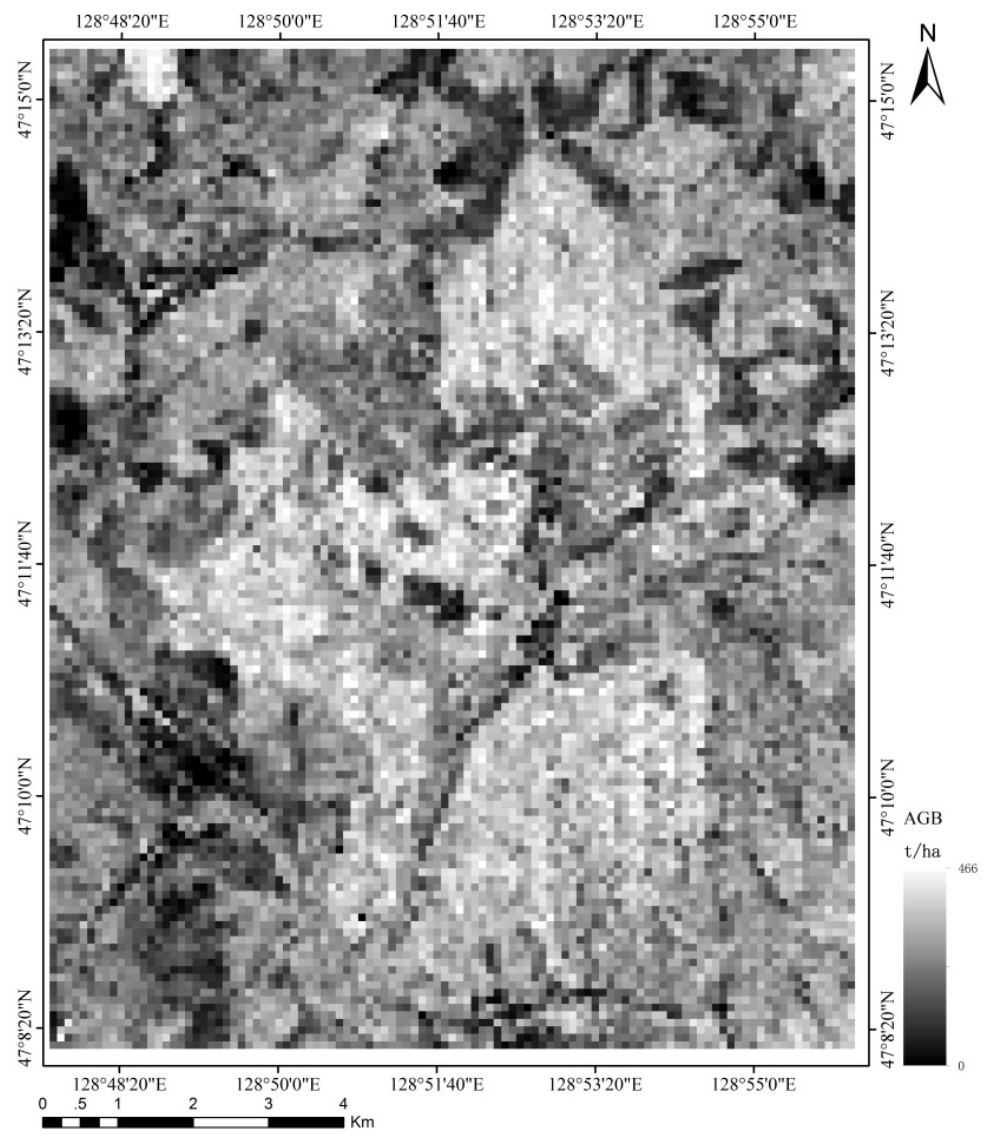

Figure 6. SVR-predicted AGB map derived by FOTO indices in the study area $(242.67 \pm 87.78 \mathrm{t} / \mathrm{ha})$.

\subsection{Intercomparison of FOTO Estimated Forest AGB Using a LiDAR-Derived AGB}

A LiDAR-derived biomass map was used for comparison with the FOTO estimated forest AGB. The FOTO-derived AGB map (Figure 6) has the same spatial pattern as the LiDAR-derived AGB map displayed in Figure 3 and has a similar shape on visual inspection (the regions of both high 
and low levels of AGB correspond to each other). Statistics results are $245.27 \pm 92.91 \mathrm{t} / \mathrm{ha}$ and $242.67 \pm 87.78 \mathrm{t} /$ ha for LiDAR-derived AGB and FOTO-derived AGB, respectively. The FOTO-derived AGB map has a coarser resolution $(100 \mathrm{~m})$ compared to the LiDAR-derived AGB map (10 m) because the spatial resolution of the FOTO output corresponds to the window size used for the 2D-FFT frequency analysis. A pixel-based validation analysis was performed after resampling the LiDAR map to the 100-m spatial resolution FOTO-derived map.

The scatterplots in Figure 7 allow for a comparison of the sampled LiDAR-derived results with the FOTO-predicted results. The regression model for the FOTO-predicted estimates coincides well with the LiDAR reference data at the pixel-scale, with an $\mathrm{R}^{2}$ of 0.79 and an RMSE of $51.08 \mathrm{t} / \mathrm{ha}$ (corresponding to a relative RMSE of 33.17\%). Residuals between the LiDAR-derived AGB and the FOTO-predicted AGB were within an acceptable range, from -120 to $160 \mathrm{t} /$ ha over the full range of AGB. Nevertheless, the residuals chart indicates that positive errors between the LiDAR-derived data and the FOTO-predicted biomass were larger than the negative errors. Specifically, underestimated situations appeared in more cases in the study area than overestimates. The statistical results listed in Table 1 suggest that the areas of larger biomass (greater than $300 \mathrm{t} / \mathrm{ha}$ ) were insufficient in the field survey compared with areas of medium level biomass (100 to $300 \mathrm{t} / \mathrm{ha}$ ); the optimal generalization results were obtained only when the training data sets were balanced in AGB distribution. The generalization ability of the FOTO indices was assessed by relating LiDAR-derived samples to FOTO-predicted samples; some uncertainty may appear due to the relationship between the above two datasets was a relative accuracy, not the absolute accuracy compared to field-derived AGB measurements.

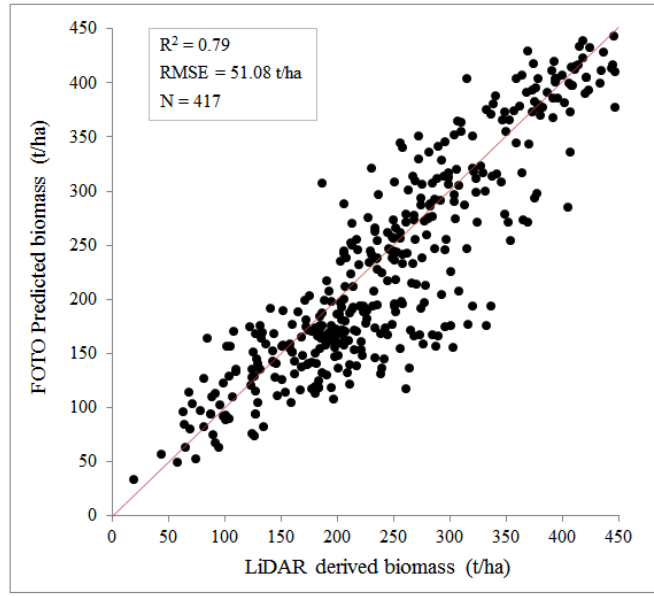

(a)

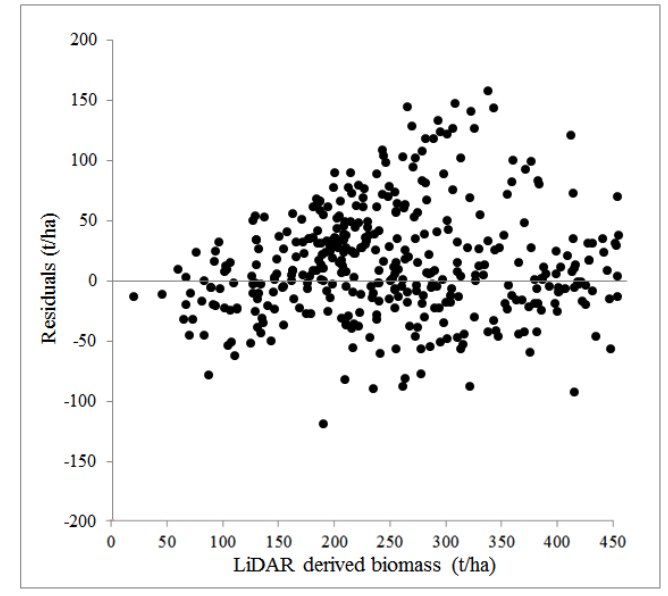

(b)

Figure 7. Validation results present (a) the correlation and (b) the residuals between the LiDAR-derived AGB and the FOTO-predicted AGB. The red line represents the 1:1 correspondence line.

\subsection{Discussion}

The purpose of this study was to analyze the relationships of FOTO indices and VHSR aerial images and the generalization performance of FOTO-predicted map over greater coverage. SVR model based on FOTO textural indices was developed to estimate forest AGB. The $\mathrm{R}^{2}$ of the best models developed for the study area was high and the RMSE was low; estimation results did not appear significantly overestimated or underestimated, and were thus promising.

Nevertheless, some critical points need to be highlighted. We orthorectified aerial images before the textural analysis, which might have had an effect on image quality, thus effecting texture information. Admittedly, it was difficult to mosaic the aerial photos together without orthorectifion. The vertical strips created by the flight trace and image mosaic affected the texture feature, while the 
window size adopted by the FOTO technique and the PCA method, which employed the r-spectra table, might have attenuated the edge effect of those vertical strips.

Texture measures are very sensitive to the spectral reflectance of forest canopy. Observations by Eckert [45] and Sarker [46] confirm that the more homogeneous a forest canopy structure is, the stronger the correlation between biomass and textural parameters. The shadow of canopy generated by terrain factors and solar elevation angles might have additionally affected the FOTO-derived results. Further investigation is required to understand the extent to which the FOTO estimation quality was affected by the terrain.

\section{Conclusions}

In this study, the FOTO texture-based approach was used to characterize texture information that was related to such forest structural parameters as canopy crown size. The AGB estimates derived from FOTO indices with an SVR modeling framework showed a strong correlation with the field-measured AGB, with $\mathrm{R}^{2}=0.88$ and RMSE $=34.35 \mathrm{t} / \mathrm{ha}$. The comparison of FOTO-derived AGB against LiDAR-derived results showed a high accuracy, with $R^{2}=0.79$ and $R M S E=51.08 \mathrm{t} / \mathrm{ha}$, which highlights the potential of the FOTO method for estimating biomass in larger regions with good accuracy. This promising performance shows that FOTO texture indices have great potential for estimating forest biomass without saturation in temperate zones; it demonstrates once again that VHSR aerial photos could be used for AGB estimation. Because high spatial resolution satellite and airborne optical images are becoming more widely available, FOTO will help to improve the efficiency and the estimation accuracy of forest monitoring and the tracking of forest biomass.

Acknowledgments: We acknowledge the support and funding from the National High-tech Research and Development Program of China (863 Program) (2012AA12A306), the National Basic Research Program of China (973 Program) (2013CB733406 \& 2013CB733404), and the Fundamental Research Funds for the Central Universities (2015KJJCA12).

Author Contributions: Shili Meng, Yong Pang and Zengyuan Li established the aims and designed the experiment. Zhongjun Zhang and Wen Jia helped analyze the data and design the figures. All authors wrote the manuscript.

Conflicts of Interest: The authors declare no conflict of interest.

\section{References}

1. United Nations Framework Convention on Climate Change. Kyoto Protocol Reference Manual on Accounting of Emissions Assigned Amount. Available online: http://unfccc.int/ (accessed on 15 March 2015).

2. Houghton, R.A. Aboveground forest biomass and the global carbon balance. Glob. Chang. Biol. 2005, 11, 945-958. [CrossRef]

3. Brown, S.; Gaston, G. African Greenhouse Gas Emission Inventories and Mitigation Options: Forestry, Land-Use Change, and Agriculture; Springer: Berlin, Germany, 1995.

4. Brown, S. Measuring carbon in forests: Current status and future challenges. Environ. Pollut. 2002, 116, 363-372. [CrossRef]

5. Zheng, D.; Rademacher, J.; Chen, J.; Crow, T.; Bresee, M.; Lemoine, J.; Ryu, S. Estimating aboveground biomass using Landsat 7 ETM+ data across a managed landscape in northern Wisconsin, USA. Remote Sens. Environ. 2004, 93, 402-411. [CrossRef]

6. Lu, D.S. The potential and challenge of remote sensing-based biomass estimation. Int. J. Remote Sens. 2007, 27, 1297-1328. [CrossRef]

7. Lu, D.; Batistella, M. Exploring TM image texture and its relationships with biomass estimation in Rondônia, Brazilian Amazon. Acta Amazon. 2005, 35, 249-257. [CrossRef]

8. Couteron, P.; Pelissier, R.; Nicolini, E.; Dominique, P. Predicting tropical forest stand structure parameters from Fourier transform of very high-resolution remotely sensed canopy images. J. Appl. Ecol. 2005, 42, 1121-1128. [CrossRef]

9. Barbier, N.; Couteron, P.; Proisy, C.; Malhi, Y. The variation of apparent crown size and canopy heterogeneity across lowland Amazonian forests. Glob. Ecol. Biogeogr. 2010, 19, 72-84. [CrossRef] 
10. Maack, J.; Kattenborn, T.; Ewald, F.F.; Enssle, F.; Hernández, P.J.; Corvalán, V.P.; Koch, B. Modeling forest biomass using Very-High-Resolution data-Combining textural, spectral and photogrammetric predictors derived from spaceborne stereo images. Eur. J. Remote Sens. 2015, 48, 245-261. [CrossRef]

11. Cedric, V.; Vepakomma, U.; Morel, J.; Bader, J.L.; Rajashekar, G.; Jha, C.S.; Ferêt, J.; Proisy, C.; Pélissier, R.; Dadhwal, V.K. Aboveground-Biomass Estimation of a Complex Tropical Forest in India Using Lidar. Remote Sens. 2015, 7, 10607-10625.

12. Bastin, J.; Barbier, N.; Couteron, P.; Adams, B.; Shapiro, A.; Bogaert, J.; de Cannière, C. Aboveground biomass mapping of African forest mosaics using canopy texture analysis: Towards a regional approach. Ecol. Appl. 2014, 24, 1984-2001. [CrossRef]

13. Singh, M.; Evans, D.; Friess, D.A.; Tan, B.S.; Chan, S.N. Mapping Above-Ground Biomass in a Tropical Forest in Cambodia Using Canopy Textures Derived from Google Earth. Remote Sens. 2015, 7, 5057-5076. [CrossRef]

14. Proisy, C.; Couteron, P.; Fromard, F. Predicting and mapping mangrove biomass from canopy grain analysis using Fourier-based textural ordination of IKONOS images. Remote Sens. Environ. 2007, 109, 379-392. [CrossRef]

15. Proisy, C.; Couteron, P.; Pelissier, R.; Engel, J. Monitoring canopy grain of tropical forest using Fourier-based textural ordination (FOTO) of very high resolution images. In Proceedings of the IEEE International Geoscience and Remote Sensing Symposium, IGARSS, Barcelona, Spain, 23-28 July 2007; pp. 4324-4326.

16. Proisy, C.; Barbier, N.; Guéroult, M.; Pélissier, R.; Gastelluetchegorry, J.P.; Grau, E.; Couteron, P. Biomass prediction in tropical forests: The canopy grain approach. In Remote Sensing of Biomass: Principles and Applications; Intech: Rijeka, Croatia, 2011; pp. 1-18.

17. Singh, M. Forest Structure and Biomass in a Mixed Forest-Oil Palm Landscape in Borneo. Master's Thesis, University of Oxford, Oxford, UK, 2012.

18. Singh, M.; Malhi, Y.; Bhagwat, S. Biomass estimation of mixed forest landscape using a Fourier transform texture-based approach on very high-resolution optical satellite imagery. Int. J. Remote Sens. 2014, 35, 3331-3349. [CrossRef]

19. Ploton, P.; Pélissier, R.; Proisy, C.; Flavenot, T.; Barbier, N.; Rai, S.N.; Couteron, P. Assessing aboveground tropical forest biomass using Google Earth canopy images. Ecol. Appl. 2012, 22, 993-1003. [CrossRef] [PubMed]

20. Lefsky, M.A.; Harding, D.; Cohen, W.B.; Parker, G.; Shugart, H.H. Surface Lidar remote sensing of basal area and biomass in deciduous forests of eastern Maryland, USA. Remote Sens. Environ. 1999, 67, 83-98. [CrossRef]

21. Englhart, S.; Keuck, V.; Siegert, F. Modeling Aboveground Biomass in Tropical Forests Using Multi-Frequency SAR Data-A Comparison of Methods. IEEE J. Sel. Top. Appl. Earth Obs. Remote Sens. 2012, 5, 298-306. [CrossRef]

22. Mora, B.; Wulder, M.A.; Hobart, G.W.; White, J.C.; Bater, C.W.; Gougeon, F.A.; Varhola, A.; Coops, N.C. Forest inventory stand height estimates from very high spatial resolution satellite imagery calibrated with LiDAR plots. Int. J. Remote Sens. 2013, 34, 4406-4424. [CrossRef]

23. GOFC-GOLD. A Sourcebook of Methods and Procedures for Monitoring and Reporting Anthropogenic Greenhouse Gas Emissions and Removals Associated with Deforestation, Gains and Losses of Carbon Stocks in Forests Remaining Forests, and Forestation; GOFC-GOLD Report Version COP19-2; GOFC-GOLD Land Cover Project Office, Wageningen University: Wageningen, The Netherlands, 2013.

24. Zhang, J.; Huang, S.; Hogg, E.H.; Lieffers, V.; Qin, Y.; He, F. Estimating spatial variation in alberta forest biomass from a combination of forest inventory and remote sensing data. Biogeosciences 2013, 10, 19005-19044. [CrossRef]

25. García-Gutiérrez, J.; Martínez-Álvarez, F.; Troncoso, A.; Riquelme, J.C. A comparison of machine learning regression techniques for lidar-derived estimation of forest variables. Neurocomputing 2015, 167, $24-31$. [CrossRef]

26. Liu, L.; Pang, Y.; Fan, W.; Li, Z.; Zhang, D.; Li, M. Fused airborne LiDAR and hyperspectral data for tree species identification in a natural temperate forest. J. Remote Sens. 2013, 17, 679-695.

27. Liu, J.; Liu, B.; Zhang, P. Scientific value and advantages of LiangShui nature conservation area. J. Wildl. 1993, 1, 4-5. (In Chinese)

28. Pang, Y.; Li, Z.Y. Inversion of biomass components of the temperate forest using airborne Lidar technology in Xiaoxing'an Mountains, Northeastern of China. Chin. J. Plant Ecol. 2012, 36, 1095-1105. [CrossRef] 
29. Wang, C. Biomass allometric equations for 10 co-occurring tree species in Chinese temperate forests. For. Ecol. Manag. 2006, 222, 9-16. [CrossRef]

30. Nilsson, M. Estimation of tree heights and stand volume using an airborne lidar system. Remote Sens. Environ. 1996, 56, 1-7. [CrossRef]

31. Næsset, E.; Gobakken, T. Estimation of above- and below-ground biomass across regions of the boreal forest zone using airborne laser. Remote Sens. Environ. 2008, 112, 3079-3090. [CrossRef]

32. Zhao, K.; Popescu, S.; Meng, X.; Pang, Y.; Agca, M. Characterizing forest canopy structure with lidar composite metrics and machine learning. Remote Sens. Environ. 2011, 115, 1978-1996. [CrossRef]

33. Magnussen, S.; Boudewyn, P. Derivations of stand heights from airborne laser scanner data with canopy-based quantile estimators. Can. J. For. Res. 1998, 28, 1016-1031. [CrossRef]

34. Robert, A. Simulation of the effect of topography and tree falls on stand dynamics and stand structure of tropical forests. Ecol. Model. 2003, 167, 287-303. [CrossRef]

35. Harrison, J.M.; Lo, C.P. PC-based two-dimensional discrete Fourier transform programs for terrain analysis. Comput. Geosci. 1996, 22, 419-424. [CrossRef]

36. Couteron, P. Quantifying change in patterned semi-arid vegetation by Fourier analysis of digitized aerial photographs. Int. J. Remote Sens. 2002, 23, 3407-3425. [CrossRef]

37. Jachowski, N.R.A.; Michelle, S.Y.Q.; Daniel, A.F.; Decha, D.; Edward, L.W.; Alan, D.Z. Mangrove biomass estimation in Southwest Thailand using machine learning. Appl. Geogr. 2013, 45, 311-321. [CrossRef]

38. Neumann, M.; Saatchi, S.S.; Ulander, L.M.H.; Fransson, J.E.S. Assessing Performance of L- and P-Band Polarimetric Interferometric SAR Data in Estimating Boreal Forest Above-Ground Biomass. IEEE Trans. Geosci. Remote Sens. 2012, 50, 714-726. [CrossRef]

39. Zeng, Z.; Hsieh, W.W.; Shabbar, A.; Burrows, W.R. Seasonal prediction of winter extreme precipitation over Canada by support vector regression. Hydrol. Earth Syst. Sci. 2011, 15, 65-74. [CrossRef]

40. Lin, X. A Simple Introduction to LIBSVM. Available online: http://www.csie.ntu.edu.tw/ cjlin/libsvm (accessed on 31 October 2015).

41. Chang, C.C.; Lin, C.J. LIBSVM: A Library for Support Vector Machines. ACM Trans. Intell. Syst. Technol. 2006, 2, 389-396. [CrossRef]

42. Smola, A.J.; Schölkopf, B. A tutorial on support vector regression. Stat. Comput. 2004, 14, 199-222. [CrossRef]

43. Varma, S.; Simon, R. Bias in error estimation when using cross-validation for model selection. BMC Bioinform. 2006, 7. [CrossRef] [PubMed]

44. Arlot, S.; Celisse, A. A survey of cross-validation procedures for model selection. Stat. Surv. 2009, 4, 40-79. [CrossRef]

45. Eckert, S. Improved Forest Biomass and Carbon Estimations Using Texture Measures from WorldView-2 Satellite Data. Remote Sens. 2012, 4, 810-829. [CrossRef]

46. Sarker, L.R.; Nichol, J.E. Improved forest biomass estimates using ALOS AVNIR-2 texture indices. Remote Sens. Environ. 2011, 115, 968-977. [CrossRef]

(C) 2016 by the authors; licensee MDPI, Basel, Switzerland. This article is an open access article distributed under the terms and conditions of the Creative Commons by Attribution (CC-BY) license (http://creativecommons.org/licenses/by/4.0/). 